\title{
LA CONSTITUCIONALIZACIÓN DEL DERECHO PRIVADO
}

\author{
David Augusto Echeverry Botero 4
}

La Academia se hace con base en las posiciones distintas que brindan temas de análisis encontrados. Les hablo de un tema que me preocupa mucho, es el tema de la constitucionalización del Derecho Privado.

Yo creo en las instituciones clásicas del Derecho Privado, claro, no me aparto de lo que debe tener una sociedad. Pero estas instituciones responden a una historia y a una tradición, a algunos sistemas jurídicos que hay que defender. Ahora estamos viendo un fenómeno donde todo se está volviendo constitucional, absolutamente todo. No se sabe si esto será bueno o malo. El Derecho Privado nace de la propiedad privada, de la garantía de la propiedad privada como fundamento del sistema jurídico. Si usted no tiene propiedad privada, ¿cómo va a hacer un intercambio? Por eso, la garantía de esos Derechos de propiedad es necesaria para los sistemas económicos. Al no estar presente, genera una de las fallas del mercado y si vemos nuestro sistema económico que enmarca el Derecho Privado y todos los temas de intercambio, tenemos que ver los artículos 333, 334 y 336 de la Constitución. Según este articulado, Colombia adopta un sistema económico de mercados y unas instituciones jurídicas que permiten que este sistema de intercambio se haga de la forma correcta, también se habla de la prohibición de los monopolios, se habla de los límites al Estado Social de Derecho. Entonces, ¿qué será la constitucionalización?, ¿realmente la Constitución tiene que matizar todo el Derecho Privado o manejarlo desde la norma Superior?, ¿eso responderá a nuestro sistema jurídico clásico y Continental? He traído una definición de un autor de la Universidad del Rosario que dice que la constitucionalización del Derecho Privado es el proceso mediante el cual las cláusulas constitucionales proyectan su eficacia jurídica sobre las instituciones clásicas del Derecho Privado y sobre las normas que los definen y desarrollan, incidiendo sobre la determinación de su alcance. Entonces pienso en los Derechos fundamentales, cómo esto matiza

4 Abogado de la Universidad Javeriana, con Maestría en derecho económico de esa misma universidad y Maestría en derecho comercial de la Universidad de Melbourne en Australia. Ha sido docente de pregrado y posgrado de las universidades Javeriana, Santo Tomás y Politécnico Grancolombiano. Ha ejercido como asesor y litigante tanto en el sector público como privado. Ha participado también en tribunales de arbitramento. 
los sistemas de intervención dentro de los mercados, lo que pasa con el libre desarrollo de la personalidad, temas que la Corte Constitucional está desarrollando. Pero ¿hasta dónde es la llamada a desarrollarlo? Por eso, mi intención es contrastar los dos sistemas jurídicos principales.

Para hablar de este tipo de temas, lo primero es contrastar cuál es el sistema clásico Continental y los sistemas de análisis que tiene cada uno de los dos sistemas jurídicos vigentes para ver. En mi concepto, la Corte Constitucional es una corte de génesis del Common Law dentro de un sistema Continental, lo que hace que nuestro sistema sea desordenado, desde mi punto de vista. Algunos dicen que existe el Derecho Vivo, la adaptación a los Derechos sociales, y yo digo ¿cuál Derecho Vivo? Si así se hacía en Roma, y ya vamos a ver porqué. Nuestro sistema Continental se basa en el silogismo. El silogismo es un término filosófico que dice es que uno parte de unas premisas. Entonces, dentro del sistema Continental partimos de una premisa mayor que es la norma, que viene después de la unión de las 12 tablas, generando estos códigos como una forma de compilación que genera una hoja de ruta para el Derecho.

Por eso todo lo vemos normatizado, los principios de la analogía y todo lo demás. ¿A qué le aplicamos esta premisa mayor? Pues a la realidad. Lo que hacían los operadores jurídicos era coger la norma y ver cómo la norma aplicaba a esa realidad para llegar a una conclusión. Si no teníamos una norma exacta (sabemos que no podemos tener todas las normas regulando el conjunto de realidades sociales), llegábamos a una conclusión que era la resolución de ese conflicto a partir de la norma.

¿Por qué les digo que se hace el Derecho como se hizo en Roma?, ¿quién sabe quiénes son los pretores?, ¿de dónde salieron esas 12 tablas que después compilaron? El pretor era el que ponía afuera su tablita y decía cuáles eran las reglas qué iba a aplicar a una situación. Entonces ya tenemos dos metodologías completamente distintas para el análisis del Derecho: una deductiva, que parte de la premisa mayor de la norma y la vamos a revisar para resolver la situación fáctica; mientras que en el Common Law se parte de una situación fáctica... ellos nunca quisieron la codificación, la gente llegaba con el problema y se resolvía con estas normas comunes bajo parámetros de justicia. En el Common Law creen en ese Derecho común, en esa esencia y en ese mundo. De ahí salen las normas y eso corresponde a una forma de sociedad, a la 
forma en que se interpreta esta. El problema se da respecto a cuántas formas de interpretación podemos tener en un momento dado.

Eso les funciona en el Common Law porque los principios están tan imbuidos dentro de la sociedad, que es algo que hace parte de la misma. Tienen la norma para resolver el caso concreto en la medida en que se presente, y por eso el sistema es completamente deductivo. Lo que busca el juez, es impartir justicia, buscar cuál es la mejor solución sin tener una norma anterior, busca resolver correctamente. A partir de eso, se genera una norma de conducta en lo que se conoce en Derecho como la ratio decidendi, bajo el principio del estare decisis, por lo que vamos a defender las decisiones anteriores. ¿A qué suena eso de tener un precedente, será propio de nuestro sistema?, ¿nuestra Constitución de cuándo viene? De 1991. ¿De cuándo venimos nosotros los civilistas? De nuestro código de 1887.

Ahí es donde se empieza a enredar el ordenamiento, porque ¿qué teníamos? Si era jurisprudencia en Colombia y en la mayoría de los sistemas continentales, una fuente del derecho auxiliar, hablamos entonces de la doctrina probable; porque los jueces no hacen leyes o normas de conducta de obligatorio cumplimiento. ¿Qué era la doctrina probable? Si uno tiene tres sentencias de la alta corte que fallaron igual, pues hay que seguir fallando igual... lo que no quiere decir que fuera de obligatorio cumplimiento, eso también motivaba la figura de la casación, La figura de la casación bajo el artículo 336 del código general del proceso lo que busca es eso, unificar la jurisprudencia y corregir los yerros judiciales. Pero siempre era bajo el entendido de que era una fuente formal del Derecho, porque los jueces no hacen leyes, son el principal operador jurídico que aplica la norma y están sometido al imperio de la norma, más en el Derecho Civil.

¿Qué dijo la Corte Constitucional en reciente sentencia? La doctrina probable se cambia por un principio de seguridad jurídica, introduciendo además el tema del precedente diciendo que el precedente sí son reglas de obligatorio cumplimiento sobre casos precisos. ¿Qué pasa con nuestro sistema? La cosa se complica todavía más con la determinación tomada por la Corte Constitucional de darle el carácter de precedente a las decisiones de las altas cortes, haciéndolas de obligatorio cumplimiento.

¿Qué quiere decir eso de precedente?, ¿cuál será la diferencia entre el precedente judicial de la Corte Constitucional y el de las otras altas cortes? Entonces, ¿dónde dejamos a la norma? Ahí vienen todas estas hermosas historias del Derecho Vivo. Cuando se habla del Derecho Vivo nos referimos a esas corrientes que dicen que el 
Derecho se tenía que adaptar a los cambios sociales, lo que se realizaba a través de la jurisprudencia, siendo labor de los jueces adaptar las leyes a los cambios sociales... la adaptación del Derecho. Ya hablaré de eso, porque se los anticipo, no hay nada más estable que el Common Law. Nosotros aquí sacamos leyes como arroz, y es una cosa muy chistosa porque en Colombia se cree que todos los problemas se solucionan con una ley. Entonces los colombianos están tristes... ¿Qué hacemos? Una ley. Tienen sueño...una ley para bajar el sueño. ¿Cuántas de esas leyes funcionan? Acá sacamos leyes todos los días, mientras que el Common Law se mantiene estable por tiempos considerables. Entonces, para que cambie un precedente dentro del Common Law se tienen que dar unos elementos fundamentales que vamos a analizar.

Ahora bien, ¿qué ha dicho la Corte Constitucional? Es más, ¿será que la Corte Constitucional está encima de las otras Cortes? Si creemos en el tema de la representatividad (democracia representativa) y la Constitución Política es la norma Suprema, esta tiene una parte orgánica, en donde debe constar quién manda a quién, quién es el superior jerárquico de la otra. ¿Alguien ha visto una norma de esas en la Constitución, que diga que la Corte Constitucional está encima de las otras cortes? No la van a encontrar. Entonces, ¿de dónde sale esa supuesta superioridad de la Corte Constitucional?

Ahí está la cosa, la misma Corte Constitucional en interpretación del artículo 241 de la Carta suprema ha dicho que, como ella es la intérprete legítima de la Constitución y la Constitución es la norma de normas, pues ella está encima en jerarquía de las demás cortes. Es la misma Corte la que lo está diciendo. ¿Y qué pasa con los temas de división de poderes? Un organismo puede asumir o definir sus propias competencias... cuando uno empieza Derecho y hace relación a Montesquieu para hablar de la división de poderes, entiende que las cortes y los jueces no son los llamados a legislar o generar normas de conducta de obligatorio cumplimiento porque no son representantes del pueblo. Pero la Corte Constitucional inclusive ha dicho que había clausulas pétreas que no podían ser modificadas por el Constituyente primario... y ¿quién es el Constituyente primario? El pueblo ¿De dónde viene el poder? Del pueblo. ¿Y cuál es el representante del pueblo? El Congreso. Pero la Corte Constitucional también ha dicho que si existen diferencias entre las normas expedidas por el Congreso y la Corte Constitucional prima la Corte Constitucional, lo que termina afectando al Derecho Privado, claro que sí. 
Hay mucha jurisprudencia en ese sentido, los invito a que la lean en sus tiempos libres, en los momentos de ocio... esas sentencias de 400 páginas... e intenten identificar la ratio decidendi, la cual es de obligatorio cumplimiento y corresponde al argumento principal que soluciona a algo que ustedes van a oír hasta que acaben su carrera: la respuesta al problema jurídico. Mientras que la obiter dicta son las demás consideraciones realizadas por la Corte para poder llegar a ese argumento principal, el decissio, que es simplemente el precedente judicial.

¿Cuál es la diferencia entre la ratio y el precedente judicial? Muy sencillo. El precedente judicial es la sentencia anterior con una situación fáctica y problema jurídico análogos para ser aplicada a casos posteriores. Pero lo qué es lo obligatorio es la ratio, inclusive en las sentencias de tutela. Se dice que las sentencias de tutela son inter partes, pero la ratio de la sentencia de tutela se volvió erga omnes cuando falla respecto a un derecho fundamental. $Y$ ¿qué es un derecho fundamental y dónde están en la Constitución?, ¿en los artículos del 11 al 41 ? Pues no. Los derechos fundamentales no están claramente definidos porque primero se hablaba de la figura de la conexidad, pero después se volvieron derechos fundamentales directos.

De ahí que, a pesar de que la tutela sea muy importante, ha habido un desbordamiento del poder y las competencias de la Corte Constitucional a partir de su aplicación. Simplemente no existen límites a ella, yo sí creo en los límites. Teniendo en cuenta la división de poderes, ¿será que una empresa netamente privada tendrá que estar pendiente de lo que dice la Corte Constitucional? Claro que sí. Acá les traigo un ejemplo, la sentencia T-375 del 97, la cual es una sentencia de tutela, parte de unos hechos relacionados con un negocio netamente comercial. Era, entre otras cosas, acerca de un tema de una negativa unilateral que el derecho de la competencia prohíbe, entonces, la ley establece regulaciones desde el cumplimiento contractual hasta sanciones administrativas por la superintendencia. Pero, en este caso, resulta que un caso netamente del Derecho Privado se puede volver constitucional en la medida en que no existan mecánicos ordinarios para solucionar la cuestión; o cuando existiendo mecanismos se puede mostrar un perjuicio irremediable. Por esto, si usted argumenta desde los derechos fundamentales, usted puede volver una controversia de naturaleza eminentemente comercial una problemática constitucional. ¿Qué les parece eso? 
Ahora hablemos de la legitimidad de una ley, ¿qué es lo que le da legitimidad a una ley?, ¿por qué tenemos que cumplir una ley?, ¿de dónde viene la ley, del legislador? Claro que sí. Y ¿por qué es obligatoria? Porque es el representante del pueblo, es un representante del pueblo y es el que tiene poder. Porque ya abandonamos esos momentos donde el monarca podía ejercer la primae noctis, ya no se puede hacer eso. ¿Saben que es la primae noctis? Bueno, se los dejo de tarea. El monarca podía ejercer los derechos absolutos antes de la generación del Estado de Derecho. Luego del cambio de poder de los monarcas al pueblo y la creación de la democracia representativa, el poder se materializa a través de las leyes, a través de un trámite legislativo lo que, en últimas, le otorga su legitimidad. Pero bueno, ¿quién elige a los jueces? En algunos sistemas de Common Law, hay elección popular de los jueces, precisamente para darle legitimidad a las normas de conducta que se tengan en determinado sistema. Pero ellos, en principio, no son representantes del pueblo.

Intervención de un asistente: usted me hace acordar de la pregunta que hicieron acerca de la legitimidad de una decisión cuando un tribunal de 9 magistrados (que no son elegidos por el pueblo), le pueda decir a los representantes del pueblo que "no". Creo que hay una serie de respuestas que ha proferido la academia italiana, alemana y la francesa al respecto. ¿Vamos a tener el gusto de poder hablar de esto?

Respuesta del profesor Echeverri: Yo vine hoy a generar controversia. Claro, la mayoría de los autores que propone son europeos, del Derecho Continental. Sin embargo, dentro del Derecho anglosajón existen respuestas diferentes... ahora veremos a McHugh, uno de los jueces de la Corte Suprema de Inglaterra, pero dentro del Derecho clásico del Common Law inglés que se aparta un poco del de los Estados Unidos. ¡Pero miren la noticia que salió hace poco de la Corte Suprema de Justicia! Dice que el juez moderno es un ser humano sensible, atento a los cambios y fenómenos sociales, con el poder de aplicar una norma legal con la óptica de lo constitucional para remover las barreras que hacen que se cometan injusticias.

¿Qué opinan de la labor del juez moderno en Colombia? En Australia, como en el clásico Derecho inglés es muy criticado el activismo judicial. Porque ¿cómo está legitimado el Common Law? En él existen los colegios de abogados donde se discute la legitimidad de una norma producida por los jueces, logrando cohesión social cuando la ley producida es la mejor para una 
determinada sociedad. Eso genera una condición porque el Common Law no es un sistema como el sistema Continental... están las normas escritas y el precedente judicial... existen constituciones con simplemente una parte orgánica. Es más, hay constituciones que ni siquiera tienen una parte dogmática, no precisan de un Bill of Rigths. No necesitaban una declaración de derechos fundamentales, porque esos parámetros están imbuidos dentro de la sociedad.

Acá dicen que cuando los jueces están generando precedentes, de facto están haciendo ley, porque son parámetros obligatorios de conducta para las personas, a pesar de no tener representatividad... entonces como no tienen representatividad, los jueces solo tienen un rol suplementario en la generación de leyes. Aquí empezamos a hablar de los límites que existen en el Common Law para generar precedentes: los jueces solo pueden hacer leyes o generar precedentes cuando el Parlamento no se ha pronunciado respecto a la materia, por el principio sustancial. Además, solo pueden hacer leyes en la medida en que les lleguen casos análogos.

Si la regla existente en forma de precedente es la mejor para la sociedad y está imbuida, al cambiarse, va a generar afectación social: por lo que es mejor mantener la norma anterior para evitar el desorden. Sí. Es un argumento un poco godo, pero así funciona.

Como limitaciones adicionales tenemos que los jueces no deben hacer política pública porque eso es competencia del Legislativo o el Ejecutivo. Los jueces están para impartir justicia, resolviendo de la mejor forma del caso que llegue a su conocimiento. Eso es lo que tienen que hacer. Ellos no tienen que pensar en aparecer en los diarios, ellos no tienen que pensar en participación en política. ¿Vieron que hace poco se están lanzando algunos exmagistrados? Ellos tienen que pensar en la justicia. Si usted está pensando en la política pública y en aparecer en los diarios, usted no puede ser objetivo y justo para resolver un caso.

Tomemos como ejemplo las decisiones frente a los derechos fundamentales y el derecho al desarrollo de la libre personalidad. ¿Serán decisiones populares?, ¿serán decisiones acordes con un contexto de una sociedad? Miren que en Colombia hay una mezcla, tenemos todos los precedentes judiciales de la Corte donde se determina el alcance y la visión de una sociedad acorde con los principios que ellos predican.

¿Pero cómo se hace la ley en el Common Law? Cosa que deberíamos enseñarle a nuestros legisladores, es que la ley va evolucionando pasito por pasito. Aquí un ejemplo. La ley de responsabilidad por producto defectuoso en Australia tiene un 
desarrollo de más de 200 años. Llegó el primer caso en 1816, lo analizaron; después llegó el segundo caso en 1837 y dijeron: "No. A esta decisión que hicimos le falta un poco, hay que extender la protección y la responsabilidad", y así paulatinamente hasta 1932. Después de eso, salió la ley en 1974. Miren que la evolución de la ley se hace por años y años para mejorar la calidad, decidiendo cada vez mejor, hasta que el Parlamento que es el Supremo reconoce que es tan buena que la eleva a los ACT.

También hay otra forma. Porque también puede haber cambios súbitos, les traigo otro ejemplo. Había una autoridad en el Common Law, como las que encontrábamos en el código civil, según la cual el esposo tiene un derecho de propiedad sobre el cuerpo de la mujer, de su esposa, del cual se derivaría el derecho legítimo al disfrute de ese cuerpo. Y, en caso de negativa, tenía derecho a demandar. Esto era así, hasta 1933, que llega el movimiento de los derechos civiles de las mujeres. Entonces, claro, a pesar de que haya un precedente, la sociedad cambió de tal forma que no es posible mantenerlo en la actualidad. Por eso, fue modificado sin necesitar una evolución de años.

Miren la magnitud del evento que tiene que haber para que haya un cambio inmediato en la ley del Common Law. El cambio tiene que ser tan evidente porque después del Siglo XX, ¿quién va a poder manifestar que el hombre tiene derecho sobre el cuerpo de la mujer? En nuestro hemisferio occidental es imposible que usted pueda mantener una ley de esas.

Estas son las limitaciones que existen en el Common Law para cuando los jueces hacen normas de conducta de obligatorio cumplimiento. La legitimidad de la ley hecha por el juez depende completamente de que esa ley cumpla con las bases sociales, con los parámetros sociales, que sea funcional. En el Common Law, los jueces son intérpretes de la sociedad, y las leyes siempre están bajo la supremacía del Parlamento. Si el parlamento considera que una ley no es buena, la puede modificar.

Surgen, entonces, las críticas más fuertes dentro del Common Law al activismo judicial. Primero, sobre la división de poderes. En Colombia, fue necesario crear el incidente de impacto fiscal para matizar los fallos. La Corte Constitucional ha dicho que no se puede argumentar el tema presupuestal para negar un derecho fundamental, por ende, están decidiendo, 
incidiendo sobre política pública. Segundo, los cambios abruptos en la ley, en el precedente cuando usted está pensando en política, se hacen ajenos a la idea de justicia. Tercero, ¿qué pasa con las fuentes del Derecho? Nosotros somos herederos del Derecho Continental francés, nosotros teníamos la estructura de fuentes del Derecho clarísima, la estructura de la ley, auxiliar, formal, doctrinal, y con eso jugábamos. ¿Qué pasa después? Nos lo modificaron a través de decisiones judiciales, que además son muy complejas. Tomen una sentencia de estas que les digo de 400 páginas y búsquenle la ratio. $\mathrm{Si}$ es difícil en las sentencias del Common Law, que no pasan de 10 páginas (la mayoría son de 3 o 4 páginas, para que la razón y la regla sean fácilmente extraíbles). Tomen una sentencia de la Corte y busquen la ratio. Muchas veces lo que está ahí, no es la razón fundamental de la decisión... además con otro agravante, la obiter de una sentencia se puede volver la ratio de otra. No estamos entrenados en este sistema de análisis. Una vez le di una conferencia a unos jueces, y los magistrados decían que esto era un problema grave. Ellos cuando están en el papel de juez de tutela fallan de una forma, y cuando están en el papel de su disciplina, fallan de otra; sin entender el funcionamiento de la una y de la otra.

Ya la Corte ha dicho que el precedente judicial es de obligatorio cumplimiento y la 1437 dice que en las sentencias de unificación del Consejo de Estado también son de obligatorio cumplimiento para los funcionarios público.

Ahora bien, seguimos con las limitaciones existentes en el Common Law. Cuarto, es necesario que tanto el problema jurídico como los hechos sean similares, si no son similares no es posible la aplicación del precedente y la ratio. Quinto, cuando la Corte hace interpretación de una ley realizada por el Parlamento (representante del pueblo) no puede modificarla, añadiéndole nada... cosa que pasa frecuentemente con las sentencias de exequibilidad o las más complicadas, las de exequibilidad condicionada; porque dicen que esta norma aplica en la medida que se aplique como lo dice la Corte Constitucional, incluso sobre los poderes del Congreso.

¿Quién controla a la Corte Constitucional? El Congreso. ¿Quién juzga a los congresistas? Las Cortes. Es un asunto complejo. Termino con esta frase, pronunciada por un gran juez del Common Law inglés, que muestra las graves falencias del sistema cuando son los jueces quienes determinan la ley sin representatividad y límites dentro de un ordenamiento jurídico: "El activismo judicial de esos fastidiosos, soberanos, civilizados, cultos y cultivados patricios de este progresismo judicial, nuestros nuevos reyes filósofos y déspotas ilustrados, están realmente aplicando los valores que ellos defienden 
y lo que ellos piensan que nosotros los pobres simples deberíamos tener, así no tengamos. $Y$ entonces las personas que se adhieren a diferentes valores o pretensiones o formas de pensar, o que tienen aspiraciones diferentes, están en el riesgo de ser fuertemente excluidas de la sociedad y ser reconocidos como enemigos de las personas". 